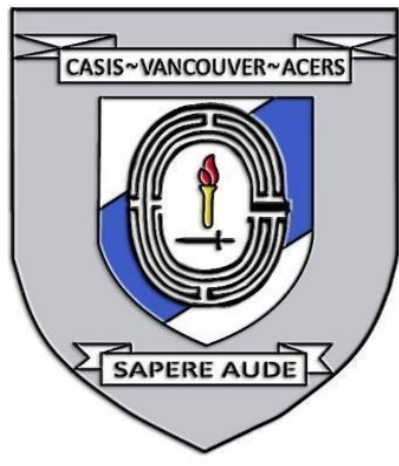

\title{
WHAT DOES SAFETY LOOK LIKE FOR YOUNG WOMEN ON THE INTERNET?
}

Date: April 30, 2021

Disclaimer: This briefing note contains the encapsulation of views presented by the speaker and does not exclusively represent the views of the Canadian Association for Security and Intelligence Studies.

\section{KEY EVENTS}

On April 23, 2021, Chloe Bynoe presented What Does Safety Look Like for Young Women on the Internet? at the 2021 CASIS Generation Z Congress. This presentation was followed by a group panel for questions and answers, whereby congress attendees were provided with an opportunity to engage in discussion with Ms. Bynoe. Primary discussion topics included online safety and security with regard to minors and online activism combating toxic culture such as misogyny.

\section{NATURE OF DISCUSSION}

\section{Presentation}

Ms. Bynoe argued that the Internet is taking away the innocence of the youth, in the sense that the online environment is perpetuating toxic masculinity and the objectification of women. Opinions from both young men and young women about masculinity and femininity are being shaped by online content, yet they may lack the means to contribute to the metanarratives.

\section{Question Period}

The discussion centered around Ms. Bynoe's perspective regarding cancel culture and online activism. Ms. Bynoe asserts that her support for cancel culture is very context dependent, and thus she may sometimes agree or disagree when someone is being cancelled. 


\section{BACKGROUND}

\section{Presentation}

Ms. Bynoe began her presentation on the safety and security of the online environment by commenting that the sexualization of young women is quite common. Misogyny harms both men and women online as it removes humanity from our society and makes generalizations about people from different groups. Ms. Bynoe then addressed what she regarded as the most pressing issues kids and youths face when they are online.

The first point discussed regarding Internet safety and security was online identity theft. Online identity theft to Gen Zs today is less about financial loss and more about reputational harm. Ms. Bynoe gave an example of how identity theft can be used for image manipulation instead of financial gain. A popular gaming YouTuber, who does not have any facial image on the Internet but is only identifiable via his voice, had his voice 'stolen.' The perpetrator, who sounds vaguely like this YouTuber, made a recording saying racial slurs and then released it on the Internet while claiming to be the YouTuber. This turned many people against the YouTuber, even though he (the YouTuber) had not done anything wrong. Given that anything put on the Internet is permanent and can be taken out of context to be used for the purposes that were not initially intended, the Internet can pose a great security risk to one's professional reputation.

The second point regarding Internet safety and security was about minors' psychological wellbeing as Internet users. Ms. Bynoe gave the example of what a 9-year-old girl had experienced. This 9-year-old created an online persona as a host of her channel and portrayed herself as a 16-year-old. Possibly due to the platform's algorithm, this 9-year-old attracted more than 200 subscribers within the first few months of hosting the channel. However, critics labeled her as toxic, problematic, and manipulative, criticisms that eventually led her to delete the channel. The challenge was that the average social media users were a lot older than this 9-year-old, and they may not have realized that they were speaking to a child when they directed criticisms at the channel host who appeared to be at least 16 years old. Consequently, this negative experience affected this girl deeply. The concern is that children must ask adults for help, but parents and guardians cannot assume that there are built-in safety features on the Internet or that online environments are always safe.

The third point regarding Internet safety and security was about creating a safe space online and holding service providers accountable. In the past, being a kid was about figuring out how to climb trees, build forts, and explore their own The Journal of Intelligence, Conflict, and Warfare Volume 4, Issue 1 
backyards, but nowadays, kids must figure out how to safely navigate the Internet in its entirety as once logged on, users can easily lose their right to privacy and the control of their images. Thus, it is important to have a safe environment where kids can express themselves without having to worry about someone trying to damage their reputation or causing psychological harm. Most importantly, in this safe space, kids must know who their friends are. Therefore, it is paramount that policymakers ensure that the Internet is a safe space for youths.

\section{Question Period}

Ms. Bynoe claims that cancel culture is necessary to a certain extent. For example, if someone is problematic in their beliefs and actively promotes harmful messages, she believes that those people should not have a platform to promote those ideas. A difference in opinions, whether it is harmful or not, may cause people to treat others differently. Ms. Bynoe argued that her support for cancel culture depends on the context of the situation.

Ms. Bynoe mentioned that she had noticed a lot of people merely band wagoning and not really looking deep into issues before giving their opinion on it. Ms. Bynoe emphasized that online activists need to know the whole story before acting on it, and they need to be accountable for their own actions.

\section{KEY POINTS OF DISCUSSION}

\section{Presentation}

- Identity theft is a real issue in today's online environment, but it is not just about financial loss, but about reputational harm as well.

- The Internet is taking away the innocence of the youth; many people do not know who someone is on the Internet or who they can trust.

- Lying about one's identity has become extremely easy and quite common. Furthermore, Internet users often lose control of privacy and their image.

- Sexualization of young women is quite common. Misogyny harms both men and women online; this removes humanity from our society and makes generalizations about people from different groups. 


\section{Question Period}

- If someone is problematic in their beliefs and actively promotes harmful messages, Ms. Bynoe believes that those people should not have a platform to promote those ideas.

- Online activists need to know the whole story before acting on it, and they need to be accountable for their own actions.

\section{(c)}

NonCommercial-NoDerivatives 4.0 International License.

\section{(C) (CHLOE BYNOE, 2021)}

Published by the Journal of Intelligence, Conflict, and Warfare and Simon Fraser University

Available from: https://jicw.org/ 